\title{
Lop Nor Revisited: Underground Nuclear Explosion Locations, 1976-1996, from Double-Difference Analysis of Regional and Teleseismic Data
}

\author{
by Felix Waldhauser, David Schaff, Paul G. Richards, ** and Won-Young Kim
}

\begin{abstract}
We have used seismic signals recorded at regional and teleseismic distances to determine precise locations of 19 underground nuclear explosions (13 in vertical shafts, and 6 in horizontal tunnels) carried out between October 1976 and July 1996 at the Lop Nor test site in the southern Xinjiang province of China. In addition to first- and later-arriving phase-pick data from the International Seismological Centre and Chinese bulletins, we use waveform cross-correlation methods to measure relative arrival times between the explosions with an accuracy of about 10 msec. We adapted the double-difference algorithm to work with regional and global network data, and applied it to the combined Lop Nor data set to remove the effects of uncertainty in the Earth model. Specifically, we determined locations of more recent tests to the accuracy of the cross-correlation data while simultaneously determining the relative locations of the older tests, for which digital waveforms are not available, to the accuracy of the phase-pick data. In general, our locations are consistent, at the $90 \%$ confidence level, with previously published locations (when compared in a common reference frame), with anthropogenic features from satellite imagery, and with high-resolution elevation data. For four explosions, however, our results indicate that a particular explosion may have been carried out in a different shaft than previously noted, or previously associated features must be ruled out because of their location outside a particular error ellipse. Mislocations of explosions from associated satellite features are less than $1 \mathrm{~km}$ for all 13 shaft events. The pattern of tunnel-explosion locations falls within a region of suitable overburden required for containment. Eighteen Lop Nor locations have solution qualities at the GT2 level or better, and are well suited to calibrate IMS stations for the purpose of monitoring compliance with the Comprehensive Nuclear-Test-Ban Treaty.
\end{abstract}

\section{Introduction}

Lop Nor, in the Xinjiang Ugar Autonomous Province of China, is known to be the site of at least 22 underground nuclear explosions (UNE) carried out between 22 September 1969 and 29 July 1996 (e.g., Yang et al., 2003). The nuclear tests, with yields between about 1 and $650 \mathrm{kt}$ (seismic magnitudes between $\mathrm{m}_{\mathrm{b}}=4.5$ and $\mathrm{m}_{\mathrm{b}}=6.5$, Yang et al., 2003), generated seismic waves that were recorded at regional and teleseismic distances. Thirteen high-yield explosions were carried out in vertical shafts (or boreholes) in the eastern area of the test site, and six low-yield explosions in horizontal tunnels (or adits) in the northwestern area (Fig. 1). The first two underground tests were carried out on 22 September 1969 and 27 October 1975 in tunnels (not shown in Fig. 1) about $35 \mathrm{~km}$ south of the northwestern area tunnel explosions. Two additional explosions, announced, for ex-

*Also at Department of Earth and Environmental Sciences. ample, in the official publication China Today: Nuclear Industry (1987), were carried out on 13 September 1979 and 16 October 1980. For the test of 13 September 1979, no information is available to determine if this undetected test was above or below ground. For the test of 16 October 1980 an origin time around 08:00 is indicated from $P$-phase picks made at Talgar and Borovoye (Kazakhstan), NORSAR (Norway), and Warramunga (Australia).

China Today: Nuclear Industry (1987) includes an appendix listing accomplishments during the period from May 1950 to December 1984, which briefly comments on the first 32 Chinese nuclear tests in ways that provide a variety of pieces of information, abstracted here in Table 1. For example, by assigning specific numbers to the first 32 tests, one may conclude that there were no other tests during this period. Subsequent to December 1984, China carried out another 13 nuclear tests, all underground. Some of the first 32 tests had seismic signals so small that these events are 


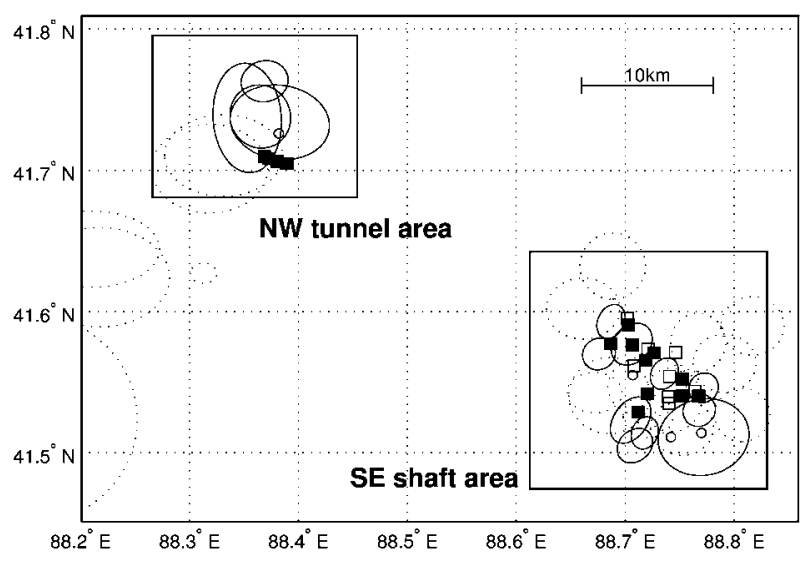

Figure 1. Lop Nor test site with southeast shaft and northwest tunnel area indicated. Squares indicate positions of shafts (southeast area) and adit entrances (northwest area) as determined from satellite imagery (Fisk, 2002; Bhattacharyya et al., 2002). Solid squares show shafts with clear satellite features that can be associated with nuclear testing, according to Bhattacharyya et al. (2002). Solid ellipses (representing errors at the $90 \%$ confidence level) and small circles (locations of fixed master events) show locations by E. Bergman and R. Engdahl (personal comm., 2001) and are based on groomed International Seismological Centre (ISC) phase picks. Dotted ellipses indicate ISC locations at the $90 \%$ confidence level for comparison.

not listed in, for example, the Bulletin of the International Seismological Centre (ISC). One particular test, that of 13 September 1979, is not associated with any signals recorded outside China. It is not stated whether this test was underground or in the atmosphere, and the only basis for claiming a test on this date is the information in China Today that the twenty-sixth test was conducted then. Including this test, China carried out a total of 45 nuclear tests prior to signing the Comprehensive Nuclear-Test-Ban Treaty (CTBT) in 1996.

No information about the accurate locations (ground truth) and origin times of the Lop Nor nuclear tests is available but is necessary for calibrating stations of the International Monitoring System (IMS) to monitor compliance with the CTBT. Thus several studies have been carried out to estimate these locations by using seismic data, sometimes combined with satellite imagery (Douglas et al., 1993; Gupta, 1995; Engdahl and Bergman, 2001; Fisk, 2002; Bhattacharyya et al., 2002; see Fisk, 2002, for a review). Many location estimates from these studies, however, differ from each other, in some cases by several kilometers (see Bhattacharyya et al., 2002, for the most recent comparison). Fisk (2002), for 11 events since 1990, obtained the most accurate locations to date by matching precise relative locations from waveform-based analysis of first-arriving $P$ phases recorded at regional and teleseismic distances with anthropogenic features that support nuclear testing seen on IKONOS satellite images. An extension of this study has been carried out by
Bhattacharyya et al. (2002) at the Center for Monitoring Research (CMR), who compiled and reviewed available location information for 21 tests (excluding the tests of 13 September 1979 and 5 October 1980 owing to lack or inadequacy of seismic observations) and adjusted the best seismic-location estimates in conjunction with commercial satellite imagery and terrain-elevation data. Their preferred locations (from now on referred to as CMR locations) include a few minor revisions (less than $500 \mathrm{~m}$ ) of the Fisk (2002) locations for post-1990 events, but for events up to 1990, shifts of up to a few kilometers were applied to previously determined locations to match them with nearby shaft or tunnel features derived from satellite images (see table $\mathrm{C}$ in Bhattacharyya et al., 2002). Both the Fisk (2002) study, using waveform data, and the Bhattacharyya et al. (2002) study, using phase picks, employed a master-event technique to locate events relative to one specific event for which the location is held fixed.

In this study our goal has been to derive as completely as possible a set of high-precision explosion locations and associated uncertainties at the Lop Nor test site. We have adapted the double-difference algorithm of Waldhauser and Ellsworth (2000), so far used with local seismic data, to work with regional and teleseismic phase-pick and cross-correlation data, to optimally determine the locations of the Lop Nor explosions in the presence of Earth model uncertainty and measurement errors in seismic arrival times. The resulting high-resolution locations and associated uncertainty estimates are compared to the CMR locations, and their association with shaft or tunnel positions derived from satellite imagery is re-evaluated.

\section{Data and Method}

To relocate the nuclear explosions we used three main data sets (see Fig. 2 for station locations):

- Phase picks based on the groomed ISC Bulletin data of Engdahl et al. (1998) (E. R. Engdahl, personal comm., 2001).

- The recently released regional phase pick data reported in the Annual Bulletin of Chinese Earthquakes (ABCE) for the 13 events between 1985 and 1996 (z-files, included in the IASPEI International Handbook of Earthquake and Engineering, Part B, 2003).

- Accurate differential travel times measured by waveform cross correlation at digital stations archived by the Incorporated Research Institutions for Seismology (IRIS) Data Management Center (DMC) and at array stations operated by the U.S. National Data Center.

Waveform cross correlation is performed in the time domain (Schaff et al., 2004) for manually adjusted windows (usually 10 to $20 \mathrm{sec}$ ) starting just before the first-arriving $P$-wave onset recorded on vertical-component seismograms. A total of 1367 differential $P$-wave arrival times are com- 
Table 1

Chinese Nuclear Tests from October 1964 to December 1984

(China Today: Nuclear Industry 1987)

\begin{tabular}{|c|c|c|c|c|c|}
\hline No. & Year & Month & Day & Hour & Note \\
\hline 1 & 1964 & 10 & 16 & $15^{*}$ & China conducted its first explosion test of the atomic-bomb device \\
\hline 2 & 1965 & 05 & 14 & & China conducted a test of a nuclear warhead (second test) \\
\hline 3 & 1966 & 05 & 09 & & China conducted a nuclear test of thermonuclear material (third test) \\
\hline 4 & 1966 & 10 & 27 & & China conducted a test of a nuclear-missile warhead (fourth test) \\
\hline 5 & 1966 & 12 & 28 & & China conducted the fifth nuclear test \\
\hline 6 & 1967 & 06 & 17 & & China conducted the first explosion test of the hydrogen-bomb device \\
\hline 7 & 1967 & 12 & 24 & & China conducted the seventh nuclear test \\
\hline 8 & 1968 & 12 & 27 & & China conducted a new thermonuclear test (eighth test) \\
\hline 9 & 1969 & 09 & $23 *$ & & China conducted the first underground nuclear test (ninth test) \\
\hline 10 & 1969 & 09 & 29 & & China conducted an explosion test of a hydrogen bomb (tenth test) \\
\hline 11 & 1970 & 10 & 14 & & China conducted the eleventh nuclear test \\
\hline 12 & 1971 & 11 & 18 & & China conducted the twelfth nuclear test \\
\hline 13 & 1972 & 01 & 07 & & China conducted the thirteenth nuclear test \\
\hline 14 & 1972 & 03 & 18 & & China conducted the fourteenth nuclear test \\
\hline 15 & 1973 & 06 & 27 & & China conducted a hydrogen-bomb test (fifteenth test) \\
\hline 16 & 1974 & 06 & 17 & & China conducted the sixteenth nuclear test \\
\hline 17 & 1975 & 10 & 27 & & China conducted an underground nuclear test (seventeenth test) \\
\hline 18 & 1976 & 01 & 23 & & China conducted the eighteenth nuclear test \\
\hline 19 & 1976 & 09 & 26 & & China conducted the nineteenth nuclear test \\
\hline 20 & 1976 & 10 & 17 & & China conducted an underground nuclear test (twentieth test) \\
\hline 21 & 1976 & 11 & 17 & & China conducted a hydrogen-bomb test (twenty-first test) \\
\hline 22 & 1977 & 09 & 17 & & China conducted the twenty-second nuclear test \\
\hline 23 & 1978 & 03 & 15 & & China conducted the twenty-third nuclear test \\
\hline 24 & 1978 & 10 & 14 & & China conducted the twenty-fourth nuclear test \\
\hline 25 & 1978 & 12 & 14 & & China conducted the twenty-fifth nuclear test \\
\hline 26 & 1979 & 09 & 13 & & China conducted the twenty-sixth nuclear test \\
\hline 27 & 1980 & 10 & 16 & & China conducted the twenty-seventh nuclear test \\
\hline 28 & 1982 & 10 & 05 & & China conducted an underground nuclear test (twenty-eighth test) \\
\hline 29 & 1983 & 05 & 04 & & China conducted an underground nuclear test (twenty-ninth test) \\
\hline 30 & 1983 & 10 & 06 & & China conducted an underground nuclear test (thirtieth test) \\
\hline 31 & 1984 & 10 & 03 & & China conducted an underground nuclear test (thirty-first test) \\
\hline 32 & 1984 & 12 & $09^{\dagger}$ & & China conducted an underground nuclear test (thirty-second test) \\
\hline
\end{tabular}

*Time is given in Beijing time. Add 8 hours for UTC. The test listed on 1969/09/23 (local time) occurred on 1969/09/22, UTC.

${ }^{\dagger}$ This date, given in China Today, appears to be in error. An underground test occurred on 19 December 1984.

puted for pairs of seismograms that have a correlation coefficient of 0.6 or above; 1147 of these measurements are obtained at array stations, from which we select 93 measurements that have the highest correlation coefficients for each array. Thus, a total of 313 cross-correlation differential times were used for relocation. An additional 14 differential times from Fisk (2002) for the two events on 25 September 1992 and 29 July 1996 in the northwestern tunnel area are included in the analysis. Figure 3 shows an example of similar waveforms for eight shaft explosions observed at station KIV about $57^{\circ}$ west of the Lop Nor test site. A measurement precision $\left(\sigma_{\mathrm{m}}\right)$ of about $0.01 \mathrm{sec}$ is determined from an analysis of the internal consistency of the measurements. The measurement precision decreases rapidly with decreasing correlation coefficient (Fig. 3). Manual inspection of additional measurements with a correlation coefficient lower than 0.6 indicates a significant decrease in measurement precision and an increase in the number of outliers.

In order to use the accurate differential time data directly, and to optimally reduce model errors between the source area and stations that recorded the events, we use the double-difference approach to the event-location problem (Waldhauser and Ellsworth, 2000). Residuals between observed travel-time differences at common stations and those calculated from the IASP91 model (Kennett and Engdahl, 1991) are minimized in an iterative weighted least-squares procedure to solve for adjustments to event separations without the use of station corrections. Initial locations used are from E. Bergman and B. Engdahl (personal comm., 2001; see also Engdahl and Bergman, 2001) (Fig. 1), as they provide location estimates for all explosions together with associated, carefully groomed, global phase data recorded at ISC stations. These locations were derived by using the hypocentral decomposition method of Jordan and Sverdrup (1981). The data set excludes many of the outliers associated with the original ISC bulletin for the Lop Nor explosions. In the application presented here we slightly damp adjustments in origin times, and keep initial depths unchanged during the inversion. We estimate initial depths, $h$, in meters for the shaft explosions using $h=120 \cdot Y^{(1 / 3)}$, with $Y$ being the yield 


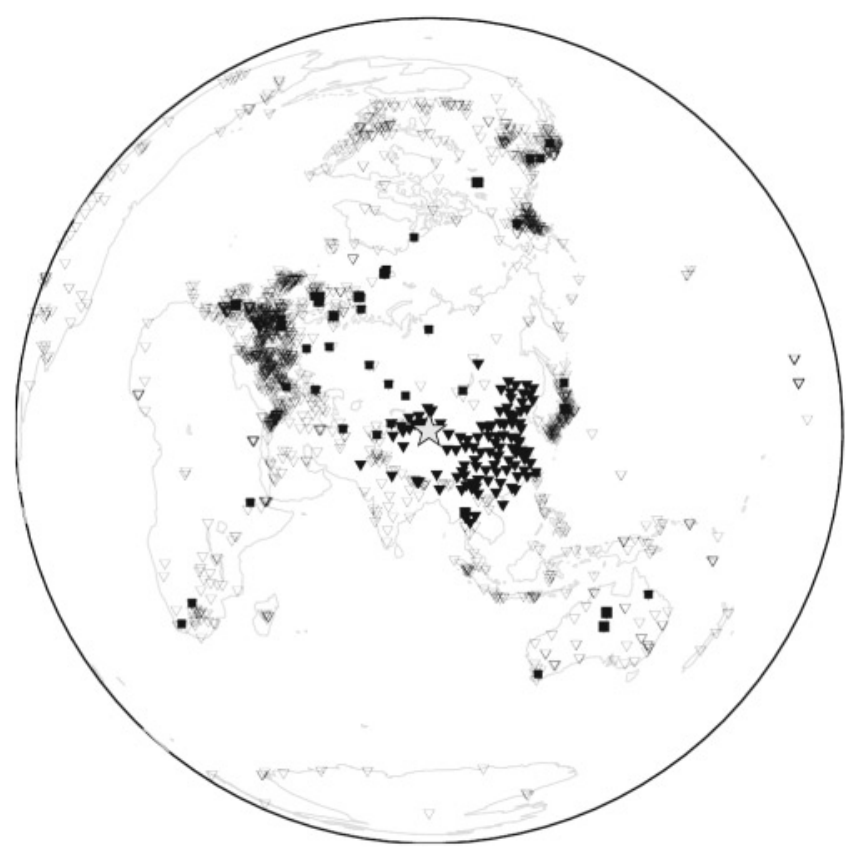

Figure 2. Map (polar projection centered at Lop Nor) showing stations that recorded the 13 shaft explosions (star): ISC stations (open triangles), stations listed in the Annual Bulletin of Chinese Earthquakes (solid triangles), and stations from the Incorporated Research Institutions for Seismology (IRIS) Data Management Center and array stations from the U.S. National Data Center (solid squares).

in kilotons. The yield is estimated from the seismic magnitude, $\mathrm{m}_{\mathrm{b}}$, by using the relationship (e.g., Ringdahl et al., 1992)

$$
m_{\mathrm{b}}=4.45+0.75 \cdot \log (Y) .
$$

Seismic magnitudes for the explosions were taken from Yang et al. (2003) (Table 2). Initial depths for the tunnel explosions are set to $100 \mathrm{~m}$. Note that slight deviations from the real depths of the explosions will have negligible effect on the estimation of the epicenters. It appears that testing was conducted in most cases on the hour, as indicated by the origin times from various sources of location parameters. Differences between Bergman's origin times for shaft explosions, for example, and the nearest full hour are only $0.088 \mathrm{sec}$ on average, with a standard deviation of $0.17 \mathrm{sec}$.

In addition to the cross-correlation data, 25,543 traveltime differences are formed from pairs of first and later arriving phase picks observed at common stations listed in the EHB and the ABCE Bulletin. To reduce errors resulting from unmodeled velocity structure, we form travel-time differences for event pairs with epicentral separations less than $10 \mathrm{~km}$ (calculated from the initial locations). Thus, we link events only within the shaft area and (separately) the tunnel area. The frequency content of teleseismic body waves is generally in the range between 0.1 and $1 \mathrm{~Hz}$ near the surface, and thus significant model errors can be introduced when shaft and tunnel events were to be linked together over distances as much as $40 \mathrm{~km}$. We observe an increase of only about $10 \%$ in the final residuals for events separated by about $7 \mathrm{~km}$, compared to events separated by a few hundred meters. Table 2 gives an overview of the connectivity between events, and lists the number and distribution of stations that recorded each event, and the number of differential times used.

The original phase data, together with the pairwise observed phases used for relocation, are shown in Figure 4 as a function of distance. Note that many of the later arriving phases listed in the bulletins were not recorded twice at a common station, or had a discrepancy in travel-time difference significantly larger than predicted from the separation of a given event pair, and were therefore discarded. The selection of pair-wise recorded phases increases pick consistency, removing some of the scatter observed in the original bulletin data (Fig. 4). Also, misassociated phases are more likely to be detected and discarded, as well as phase arrival times at stations with significant clock errors. In a few cases, however, such as the ABCE travel times of about $550 \mathrm{sec}$ and $750 \mathrm{sec}$ at about $4^{\circ}$ distance (arrows in Fig. 4), signals appear to be wrongly identified as being a $P$ phase for more than one event (they appear to be $P c P$ and $P c S$, respectively). Such problematic data, however, are downweighted and eventually removed during the iterative relocation process. An iteration-dependent scheme is employed to weight the data according to the a priori data quality, the distance between events, and the performance during each inversion (see Waldhauser, 2001, for details). Errors at the 90\% confidence level are determined by fitting an ellipse to the scatter of 200 bootstrap realizations obtained by repeated resampling of the final double-difference vector and subsequent relocation (see Waldhauser and Ellsworth, 2000).

\section{Results}

Figure 5a shows double-difference results for the 13 shaft explosions, together with the positions of vertical shafts identified on IKONOS satellite imagery (Fisk, 2002; Bhattacharyya et al., 2002). Shaft features are indicated by circles with sizes equal to the sizes of their estimated relative location uncertainties of about $200 \mathrm{~m}$, the worst-case accuracy in picking the shaft locations. Most of the newer shafts are very clear, whereas the older shafts are difficult to resolve because of erosion. With the worst-case registration accuracy being about $300 \mathrm{~m}$, the absolute location uncertainty of the shafts amounts to about $500 \mathrm{~m}$ (see the CMR Web site, www.cmr.gov/rdss/resources/satimage/LopNor/LopNor East01/index.html for detailed location and uncertainty information). This should be considered the upper bound on the overall absolute accuracy, as it assumes that the errors are totally correlated, which is not the case (M. Fisk and B. Kohl, personal comm., 2004). The features showing nucleartesting activity are well defined for candidate shaft locations 


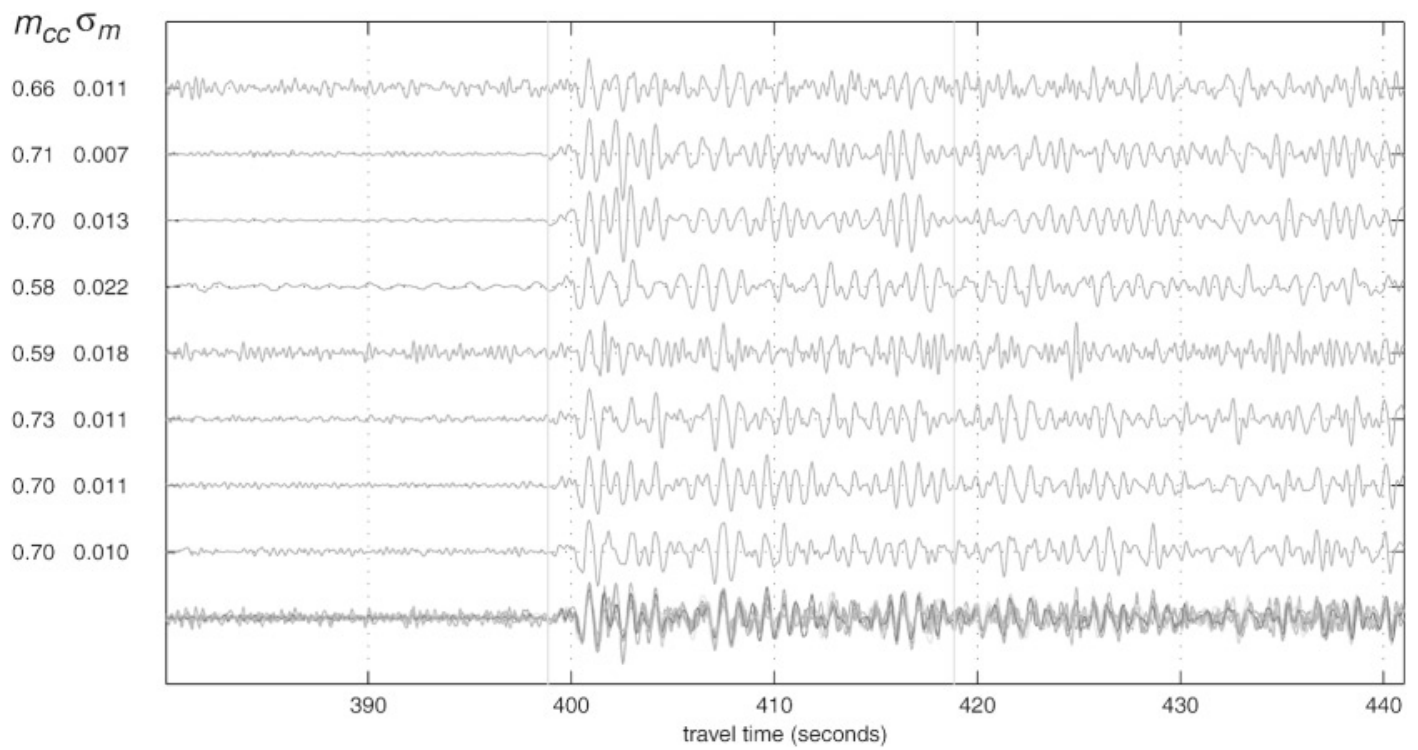

Figure 3. Waveforms recorded at stations KIV, about $57^{\circ}$ west of the Lop Nor test site. Values in the left column indicate mean cross-correlation coefficients, $m_{\mathrm{cc}}$, for 20 sec time windows (between about 399 and $419 \mathrm{sec}$ ), and measurement errors $\sigma_{\mathrm{m}}$ (right column, in sec) as determined from the internal consistency of the differential time measurements. Bottom trace shows superposition of the aligned waveforms shown above.

Table 2

Station Distribution and Connectivity between Events

\begin{tabular}{lccccccc}
\hline Explosion Date & $m_{\mathrm{b}}{ }^{*}$ & $\begin{array}{c}\text { Number of } \\
\text { Stations }^{\dagger}\end{array}$ & $\begin{array}{c}\text { Distance to } \\
\text { Nearst Station } \\
(\mathrm{km})\end{array}$ & $\begin{array}{c}\text { Max. Azimuth } \\
\text { Gap }\left(^{\circ}\right)\end{array}$ & $\begin{array}{c}\text { Number of } \\
\text { Events Linked }\end{array}$ & $\begin{array}{c}\text { Number of } \\
\text { Diff. Times }\end{array}$ & $\begin{array}{c}\text { Shaft/ } \\
\text { Tunnel }\end{array}$ \\
\hline $1976 / 10 / 17$ & 4.9 & $34 / 0$ & 1767 & 104 & 5 & $66 / 0$ & $\mathrm{~T}$ \\
$1978 / 10 / 14$ & 4.9 & $21 / 0$ & 2325 & 187 & 10 & $187 / 0$ & $\mathrm{~S}$ \\
$1983 / 05 / 04$ & 4.5 & $5 / 0$ & 2336 & 236 & 5 & $16 / 0$ & $\mathrm{~T}$ \\
$1983 / 10 / 06$ & 5.5 & $51 / 2$ & 965 & 65 & 11 & $355 / 5$ & $\mathrm{~S}$ \\
$1984 / 10 / 03$ & 5.2 & $42 / 5$ & 967 & 65 & 11 & $296 / 14$ & $\mathrm{~S}$ \\
$1984 / 12 / 19$ & 4.7 & $39 / 1$ & 238 & 62 & 5 & $82 / 1$ & $\mathrm{~T}$ \\
$1987 / 06 / 05$ & 6.3 & $140 / 14$ & 495 & 43 & 11 & $850 / 26$ & $\mathrm{~S}$ \\
$1988 / 09 / 29$ & 4.7 & $44 / 1$ & 236 & 78 & 5 & $82 / 1$ & $\mathrm{~T}$ \\
$1990 / 05 / 26$ & 5.5 & $104 / 5$ & 492 & 43 & 12 & $723 / 21$ & $\mathrm{~S}$ \\
$1990 / 08 / 16$ & 6.2 & $190 / 13$ & 602 & 32 & 9 & $1115 / 37$ & $\mathrm{~S}$ \\
$1992 / 05 / 21$ & 6.5 & $211 / 19$ & 498 & 36 & 10 & $1188 / 39$ & $\mathrm{~S}$ \\
$1992 / 09 / 25$ & 5.0 & $79 / 20$ & 238 & 44 & 5 & $101 / 20$ & $\mathrm{~T}$ \\
$1993 / 10 / 05$ & 5.9 & $177 / 18$ & 1177 & 93 & 4 & $1118 / 51$ & $\mathrm{~S}$ \\
$1994 / 06 / 10$ & 5.8 & $145 / 6$ & 494 & 34 & 11 & $964 / 26$ & $\mathrm{~S}$ \\
$1994 / 10 / 07$ & 6.0 & $160 / 10$ & 604 & 35 & 12 & $1067 / 41$ & $\mathrm{~S}$ \\
$1995 / 05 / 15$ & 6.1 & $195 / 30$ & 496 & 18 & 11 & $1119 / 74$ & $\mathrm{~S}$ \\
$1995 / 08 / 17$ & 6.0 & $174 / 26$ & 601 & 25 & 11 & $1025 / 57$ & $\mathrm{~S}$ \\
$1996 / 06 / 08$ & 5.9 & $176 / 33$ & 490 & 29 & 9 & $1015 / 67$ & $\mathrm{~S}$ \\
$1996 / 07 / 29$ & 4.9 & $65 / 20$ & 638 & 44 & 5 & $85 / 20$ & $\mathrm{~T}$ \\
\hline
\end{tabular}

*Magnitudes, $m_{\mathrm{b}}$, from Yang et al. (2003).

Total number of stations/number of stations with cross-correlation measurements.

${ }^{*}$ Total number of different times/number of cross-correlation different times.

A2, B1, C1, D1, D2, E2, K1, L1, N2, and O1 (solid gray circles, Fig. 5a), and less well defined for remaining shafts A1, E1, H1, I1, J1, M1, M2, and N1 (open circles) (Bhattacharyya et al., 2002).

Table 3 summarizes the new shaft-explosion locations and error estimates. The major axes of the $90 \%$ error ellipses of the shaft explosions are mostly oriented northeast and range between 0.83 and $3.39 \mathrm{~km}$. The root mean square (rms) of the differential travel-time residuals of all 13 shaft explosions is $142 \mathrm{msec}$ for the phase-pick data and $63 \mathrm{msec}$ 


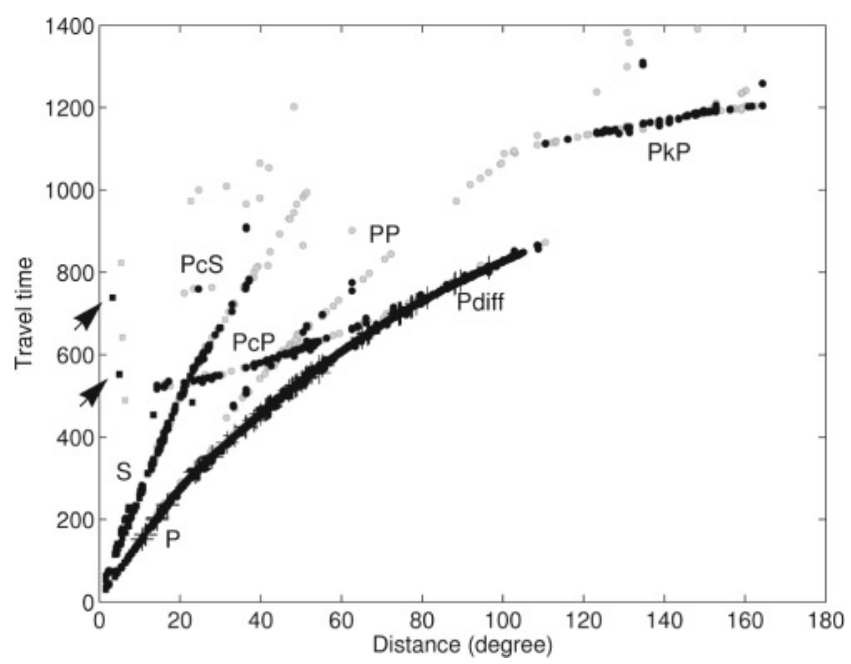

Figure 4. A total of 8412 travel times of EHBbased (gray dots) and ABCE (gray squares) phases, and 7596 travel times (black dots, EHB, and squares, $\mathrm{ABCE}$, respectively) of phases observed for pairs of shaft events, shown as a function of distance. Phase arrival times for which arrival-time differences were determined from waveform cross correlation are indicated with a plus symbol $(+)$. For explanation of arrows, see text.

for the cross-correlation data. Before relocation the rms residuals were $567 \mathrm{msec}$ and $370 \mathrm{msec}$ for the phase-pick and cross-correlation data, respectively, based on the initial locations. Residuals between individual events are similar because they are linked to almost all other events (see Table 2 ), and therefore they reflect an average across the events to which they are linked. To verify the consistency of the new explosion locations with the previously assigned shaft locations, the centroid of the double-difference (DD) locations (i.e., the pattern of relative DD locations) is shifted to match the centroid of the respective shaft locations preferred by the CMR study (gray ellipses in Fig. 5a). After a reevaluation of the shaft associations (see following text), the final DD locations (black circles in Fig. 5a; Table 3) are determined by moving the centroid of the DD locations to the centroid of our preferred shaft locations, minimizing the sum of all mislocation vectors. Note that the difference between the two centroids before and after reevaluation is small (about 100 $\mathrm{m}$ ), as only a few changes in shaft associations are proposed in this study (see following text).

Analyses of the tunnel explosions were more difficult to perform mainly because of the limited number of recordings, owing to their lower yields and earlier dates. Figure $5 \mathrm{~b}$ shows results for the six explosions, and Table 4 lists the location parameters. Figure $5 \mathrm{~b}$ also indicates the locations of tunnel (or adit) entrances (filled squares, T1-T4) determined by Fisk (2002) and Bhattacharyya et al. (2002) from IKONOS satellite data. The adit entrances have a relative location accuracy of $100 \mathrm{~m}$, and the absolute location accuracy is about $500 \mathrm{~m}$, similar to the shaft locations.
Similar to the shaft-explosion solutions, the semimajor axes of the $90 \%$ error ellipses are generally oriented northeast and range between 0.6 and $2.1 \mathrm{~km}$, except for the event of 4 May 1983. This event is only weakly constrained, as it was recorded at only 9 ISC stations, 6 of which also recorded one or more other tunnel explosions. The resulting error ellipse has a semimajor axis of $12.6 \mathrm{~km}$. We downweighted events 7610,8305 , and 8412 relative to the newer tests, because of the lower number and quality of phase picks available as well as stations at distances greater than about 5000 $\mathrm{km}$. The rms of the differential travel-time residuals (excluding event 8305) are $790 \mathrm{msec}$ for the phase-pick data and $15 \mathrm{msec}$ for the cross-correlation data, similar to the measurement error. Before relocation, the rms were 1600 and $520 \mathrm{msec}$ for the phase-pick and cross correlation data, respectively. The DD location pattern has been shifted so that the centroid of events 9209 and 9607 matches the centroid of the two corresponding CMR locations.

Figure 6 shows polar plots of the final rms station residuals for the shaft and tunnel explosions. They indicate a fairly good azimuthal coverage (see also Table 2), with residuals reaching $0.37 \mathrm{sec}$ for the shaft events and $2.0 \mathrm{sec}$ for the tunnel events. The largest residuals for the tunnel events are caused by event 8305 , for which the few stations available were included even if they had large residuals in comparison with the other events. Figure 6 also shows the somewhat sparse distribution of recordings in the former Soviet Union, which results in the general northeast elongation of the error ellipses (Fig. 5). The southeast-northwest direction is well constrained by the numerous stations listed in the $\mathrm{ABCE}$ and stations in Europe.

\section{Discussion}

Figure 5a and Table 3 indicate that all DD locations have at least one shaft feature, including our preferred shafts (marked with a "plus" symbol, +, in Fig. 5a), within, or not more than $200 \mathrm{~m}$ outside, their error ellipses. In general, the DD solutions are consistent with the results from Fisk (2002) and Bhattacharyya et al. (2002), but a few differences exist (Fig. 7a). For 7 of the 13 explosions the shaft closest to the DD locations is also the preferred shaft of Bhattacharyya et al. (2002) for the corresponding event, except for event 9310. The shaft closest to 9310 is A1, but we have assigned slightly more distant shaft A2 to this event because A2 has man-made surface artifacts that are consistent with known shaft sites, whereas the features at A1 are less clear (Fisk, 2002). In three cases (events 7810,8410 , and 9310) the shafts closest to the DD locations (L1, H1, and A1, respectively) differ from the shafts preferred by Bhattacharyya $e t$ al. (2002) (N2, D2, and A2, respectively), but their shafts are included in the $90 \%$ error ellipses of the DD locations. Finally, for three events $(9005,9008$, and 9205) the shafts chosen by Bhattacharyya et al. (2002) (E2, M1, and N1, respectively) are not included in the DD error ellipses.

Our results confirm the CMR shaft associations for 9 

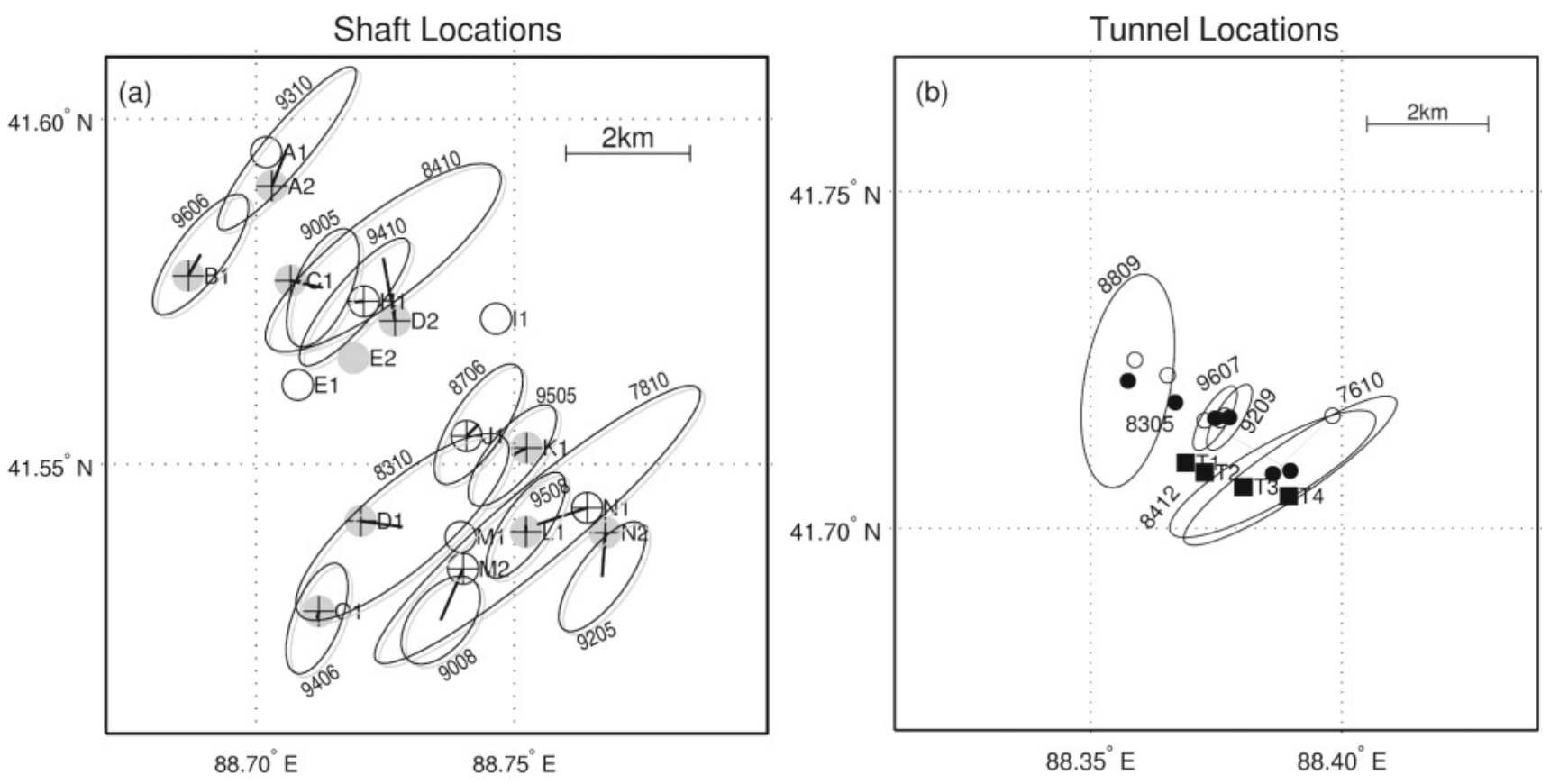

Figure 5. Double-difference (DD) results for (a) 13 shaft explosions (see Table 3) and (b) 6 tunnel explosions (Table 4). DD locations are represented by $90 \%$ error ellipses and are labeled by year and month of occurrence. In (a) final locations are in black and centered on our preferred shafts; gray ellipses are centered on the shafts preferred by Bhattacharyya et al. (2002) for comparison. The locations of shafts with clear (gray filled circles) and less clear (open circles) satellite features that support nuclear testing are indicated, with circle size proportional to their relative-location uncertainty. Plus symbols $(+)$ mark shafts that we associate with nuclear-testing activity, and lines connect these shafts to the corresponding explosion locations. In (b) adit entrances are indicated by squares. DD locations (dots) and corresponding CMR locations (open circles) are connected by lines. The centroid of events 9209 and 9607 is the same for both sets of locations. Note that the error ellipse of the 8305 event is too large to be shown on this plot. Shaft and adit labels are as shown in Bhattacharyya et al. (2002).

events, but lead us to reassign shaft associations for the remaining 4 events (7810, 9005, 9008, and 9205), to which we assign shafts $\mathrm{N} 1, \mathrm{C} 1, \mathrm{M} 2$, and $\mathrm{N} 2$, respectively (Table 3; Fig. 7a).

Event 9205 is assigned to shaft N2. This event was assigned to shaft N1 by Bhattacharyya et al. (2002, Fig. 2). On the basis of our DD results, the younger age of the test (1992), and the indication that shaft N2 has better-defined features than N1 (Bhattacharyya et al., 2002), we associate this event with shaft N2. This is also in accordance with Fisk (2002), who originally assigned 9205 to shaft N2 (shaft 13 in his figure 10).

Event 7810 is assigned to shaft N1. This event was assigned to shaft N2 by Bhattacharyya et al. (2002), but we assign shaft $\mathrm{N} 1$ to this event because (1) N1 is closer to the DD locations than N2, and (2) N2, with well-defined features, is already assigned to more recent event 9205 (see previous text), whereas $\mathrm{N} 1$, with eroded features, correlates better with older test 7810, carried out in 1978.

Event 9008 is assigned to shaft M2. It was assigned to shaft M1 by Bhattacharyya et al. (2002), a shaft slightly closer to the Fisk (2002) location than shaft M2, with both shafts touching Fisk's error ellipse. The DD location is about $1.5 \mathrm{~km}$ south of the Fisk location, and the DD error ellipse touches shaft M2 but does not include shaft M1. Since both shafts show less-well-defined satellite features (Bhattacharyya et al., 2002), we assign shaft M2 to event 9008 . We have not assigned another event to shaft M1 (Fig. 7a).

Event 9005 is assigned to shaft $\mathrm{C} 1$. This is the only event for which we have a clear discrepancy between the Fisk (2002) solution and our DD solution (Fig. 7a). Our error ellipse for this explosion includes shaft $\mathrm{C} 1$, whereas the Fisk solution is about $1.5 \mathrm{~km}$ to the south-southeast and includes shaft E2. Both shafts have well-defined satellite-imagery features. Note that in Fisk's (2002) study the 9005 event, with nine defining phases, appears to be the least constrained solution in terms of number of stations.

On the basis of our solutions shown in Figure 7a, it may also be possible that older event 8410 was carried out in shaft $\mathrm{H} 1$ that actually shows eroded features, whereas more recent event 9410 could have been carried out in shaft D2 that shows well-defined features on the satellite imagery. We 
Table 3

Double-Difference Locations of Shaft Explosions

\begin{tabular}{|c|c|c|c|c|c|c|c|c|c|c|c|}
\hline Date & Time* & $\mathrm{Lat}^{\dagger}$ & Long..$^{\dagger}$ & $\begin{array}{c}\text { Depth* } \\
(\mathrm{km})\end{array}$ & $\begin{array}{l}\text { Smaj } \\
\text { Axis }^{\sharp}\end{array}$ & $\begin{array}{l}\text { Smin } \\
\text { Axis }^{\ddagger}\end{array}$ & Strike & $\begin{array}{l}\text { Possible } \\
\text { Shafts }\end{array}$ & $\begin{array}{l}\text { Pref. } \\
\text { Shaft" }\end{array}$ & $\Delta^{\#}$ & $\mathrm{GT}^{* *}$ \\
\hline $1978 / 10 / 14$ & 01:00:00.17 & 41.5413 & 88.7545 & 0.2 & 3.39 & 0.58 & $50^{\circ}$ & $\begin{array}{l}\text { L1 } \\
\text { N1 } \\
\text { N2 } \\
\text { M1 } \\
\text { M2 }\end{array}$ & $\begin{array}{c}\mathrm{N} 1 \\
\text { (N2) }\end{array}$ & $\begin{array}{c}0.84 \\
(1.73)\end{array}$ & $2(5)$ \\
\hline $1983 / 10 / 06$ & 10:00:00.14 & 41.5409 & 88.7283 & 0.4 & 2.18 & 0.67 & $50^{\circ}$ & $\begin{array}{l}\mathrm{D} 1 \\
\mathrm{M} 1 \\
\mathrm{O} 1 \\
\mathrm{~J} 1\end{array}$ & D1 & $\begin{array}{c}0.68 \\
(1.15)\end{array}$ & $2(2)$ \\
\hline $1984 / 10 / 03^{\dagger \dagger}$ & 06:00:00.08 & 41.5799 & 88.7246 & 0.3 & 2.33 & 0.67 & $53^{\circ}$ & $\begin{array}{l}\mathrm{H} 1 \\
\mathrm{D} 2 \\
\mathrm{C} 1\end{array}$ & D2 & $\begin{array}{c}1.03 \\
(0.44)\end{array}$ & $2(1)$ \\
\hline 1987/06/05 & 05:00:00.48 & 41.5558 & 88.7431 & 0.8 & 1.12 & 0.41 & $34^{\circ}$ & $\mathrm{J} 1$ & $\mathrm{~J} 1$ & $\begin{array}{c}0.27 \\
(1.52)\end{array}$ & $1(2)$ \\
\hline $1990 / 05 / 26$ & 08:00:00.04 & 41.5756 & 88.7130 & 0.4 & 1.02 & 0.44 & $24^{\circ}$ & $\begin{array}{l}\mathrm{C} 1 \\
\mathrm{H} 1\end{array}$ & $\begin{array}{c}\mathrm{C} 1 \\
\text { (E2) }\end{array}$ & $\begin{array}{c}0.50 \\
(0.40)\end{array}$ & $1(1)$ \\
\hline $1990 / 08 / 16$ & 05:00:00.05 & 41.5274 & 88.7358 & 0.7 & 0.83 & 0.47 & $39^{\circ}$ & M2 & $\begin{array}{l}\text { M2 } \\
\text { (M1) }\end{array}$ & $\begin{array}{c}0.91 \\
(0.41)\end{array}$ & $2(1)$ \\
\hline $1992 / 05 / 21$ & $04: 59: 59.84$ & 41.5337 & 88.7670 & 1.0 & 1.05 & 0.39 & $36^{\circ}$ & $\mathrm{N} 2$ & $\begin{array}{c}\mathrm{N} 2 \\
\text { (N1) }\end{array}$ & $\begin{array}{c}0.71 \\
(0.37)\end{array}$ & $2(1)$ \\
\hline $1993 / 10 / 05$ & 01:59:59.69 & 41.5957 & 88.7060 & 0.5 & 1.69 & 0.35 & $40^{\circ}$ & $\begin{array}{l}\text { A1 } \\
\text { A2 }\end{array}$ & $\mathrm{A} 2$ & $\begin{array}{c}0.65 \\
(0.21)\end{array}$ & $2(1)$ \\
\hline $1994 / 06 / 10$ & $06: 26: 00.19$ & 41.5277 & 88.7118 & 0.5 & 0.94 & 0.38 & $22^{\circ}$ & $\mathrm{O} 1$ & O1 & $\begin{array}{c}0.12 \\
(0.44)\end{array}$ & $1(1)$ \\
\hline $1994 / 10 / 07$ & 03:26:00.18 & 41.5735 & 88.7191 & 0.6 & 1.31 & 0.35 & $40^{\circ}$ & $\begin{array}{l}\mathrm{H} 1 \\
\mathrm{E} 2\end{array}$ & $\mathrm{H} 1$ & $\begin{array}{c}0.15 \\
(0.40)\end{array}$ & $1(1)$ \\
\hline $1995 / 05 / 15$ & 04:06:00.20 & 41.5513 & 88.7496 & 0.7 & 1.01 & 0.38 & $40^{\circ}$ & K1 & K1 & $\begin{array}{c}0.26 \\
(0.24)\end{array}$ & $1(1)$ \\
\hline $1995 / 08 / 17$ & 01:00:00.14 & 41.5412 & 88.7522 & 0.6 & 1.00 & 0.36 & $34^{\circ}$ & L1 & L1 & $\begin{array}{c}0.11 \\
(0.08)\end{array}$ & $1(1)$ \\
\hline $1996 / 06 / 08$ & 02:56:00.06 & 41.5804 & 88.6893 & 0.5 & 1.17 & 0.39 & $37^{\circ}$ & B1 & B1 & $\begin{array}{c}0.40 \\
(0.09)\end{array}$ & $1(1)$ \\
\hline
\end{tabular}

\footnotetext{
*Initial depths were kept fixed during the inversion, whereas some damping is applied to origin-time adjustments. Note that the tests appear to have been carried out on the full hours.

'Locations centered at the centroid of our preferred shaft locations (see plus symbol, +, in Fig. 5a).

Femimajor and semiminor axes of the $90 \%$ error ellipses are in $\mathrm{km}$. Strike is orientation of semimajor axis, clockwise from north.

${ }^{\S}$ Shafts on or within the $90 \%$ confidence error ellipses of the double-difference (DD) location, ordered by distance from DD epicenter.

"Preferred shaft; i.e., shaft closest to DD location, except for events 1978/10/14 and 1984/10/03 (see text). In parentheses: shaft preferred by Fisk (2002)/ Bhattacharyya et al. (2002). Shaft labels in italic indicate features less well defined on the satellite imagery.

"Distance between DD location and assigned shaft, in km (thick black line in Fig. 7a). In parentheses: distance from original locations of Fisk (2002) (for events 1990-1996), and Bhattacharyya et al. (2002) to their preferred shaft, before adjustment (red/blue lines in Fig. 7a).

**GT level (rounded to the next larger $\mathrm{km}$ ) is obtained by adding the distance of the explosion to the assigned shaft (see') and the upper bound of an absolute shaft location uncertainty of $500 \mathrm{~m}$. Note that this shaft uncertainty is very conservative and is likely to be less for newer shafts with clear features. GT levels determined by Bhattacharyya et al. (2002) are indicated in parentheses.

${ }^{\dagger}$ Gupta (1995) determined a satellite photo location (41.5713/88.7216) for the shaft of this event, which is less than $1 \mathrm{~km}$ away from the DD location.
}

assume that only one test was carried out in each of the shafts.

The tunnel tests are difficult to locate in an absolute sense, because satellite-imagery features $\mathrm{T} 1, \mathrm{~T} 2, \mathrm{~T} 3$, and $\mathrm{T} 4$ (Figs. 5b, 7b) are adit entrances that do not colocate with the epicentral location of particular explosions. Fisk (2002) and Bhattacharyya et al. (2002) analyzed these entrances, together with the seismically determined relative explosion locations and terrain elevation data, at approximately $1-\mathrm{km}$ resolution (USGS GTOPO30) to determine their preferred locations (CMR locations, small open circles in Fig. 7b). A critical constraint on the location of the nuclear explosions relative to the tunnel entrances is the topographic relief in the vicinity of the entrances, as the explosions require suitable overburden for containment. We use Shuttle Radar Topography Mission (SRTM) data with a resolution of approximately $90 \mathrm{~m}$ (Fig. 7b) to map out in detail potential areas with appropriate overburden for underground nuclear testing. We consider such areas to have topographic data that indicate at least $100 \mathrm{~m}$ of relief with respect to the elevations of the adit entrances. The adit entrances, based on the SRTM data, have elevations of $1525 \mathrm{~m}$ (T1), $1492 \mathrm{~m}$ (T2), $1513 \mathrm{~m}$ 
Table 4

Double-Difference Locations of Tunnel Explosions

\begin{tabular}{|c|c|c|c|c|c|c|c|c|}
\hline Date & Time* & $\mathrm{Lat}^{\dagger}$ & Long $^{\dagger}$ & Depth* & Smaj Axis & Smin Axis $^{\ddagger}$ & Strike & $\mathrm{GT}^{\S}$ \\
\hline $1976 / 10 / 17$ & 05:00:00.82 & 41.7086 & 88.3897 & 0.1 & 2.1 & 0.4 & $56^{\circ}$ & $2(2)$ \\
\hline $1983 / 05 / 04$ & 05:00:00.31 & 41.7187 & 88.3669 & 0.1 & 12.6 & 8.3 & $68^{\circ}$ & $3(3)$ \\
\hline $1984 / 12 / 19$ & 05:59:59.82 & 41.7081 & 88.3862 & 0.1 & 1.9 & 0.5 & $60^{\circ}$ & $2(2)$ \\
\hline $1988 / 09 / 29$ & 07:00:00.49 & 41.7219 & 88.3574 & 0.1 & 1.8 & 0.7 & $10^{\circ}$ & $2(2)$ \\
\hline $1992 / 09 / 25$ & 08:00:00.56 & 41.7165 & 88.3776 & 0.1 & 0.6 & 0.2 & $32^{\circ}$ & $2(2)$ \\
\hline $1996 / 07 / 29$ & 01:49:00.17 & 41.7163 & 88.3748 & 0.1 & 0.6 & 0.2 & $32^{\circ}$ & $2(2)$ \\
\hline
\end{tabular}

*Initial depths were kept fixed during the inversion, whereas some damping is applied to origin-time adjustments.

thocations centered at the CMR locations (black dots in Fig. 5b).

F Semimajor and semiminor axes of the $90 \%$ error ellipses are in $\mathrm{km}$. Strike is orientation of semimajor axis, clockwise from north.

${ }^{\S}$ The GT level is determined by averaging over the two semi-axes of the error ellipses. Note that the absolute location uncertainty may be larger.
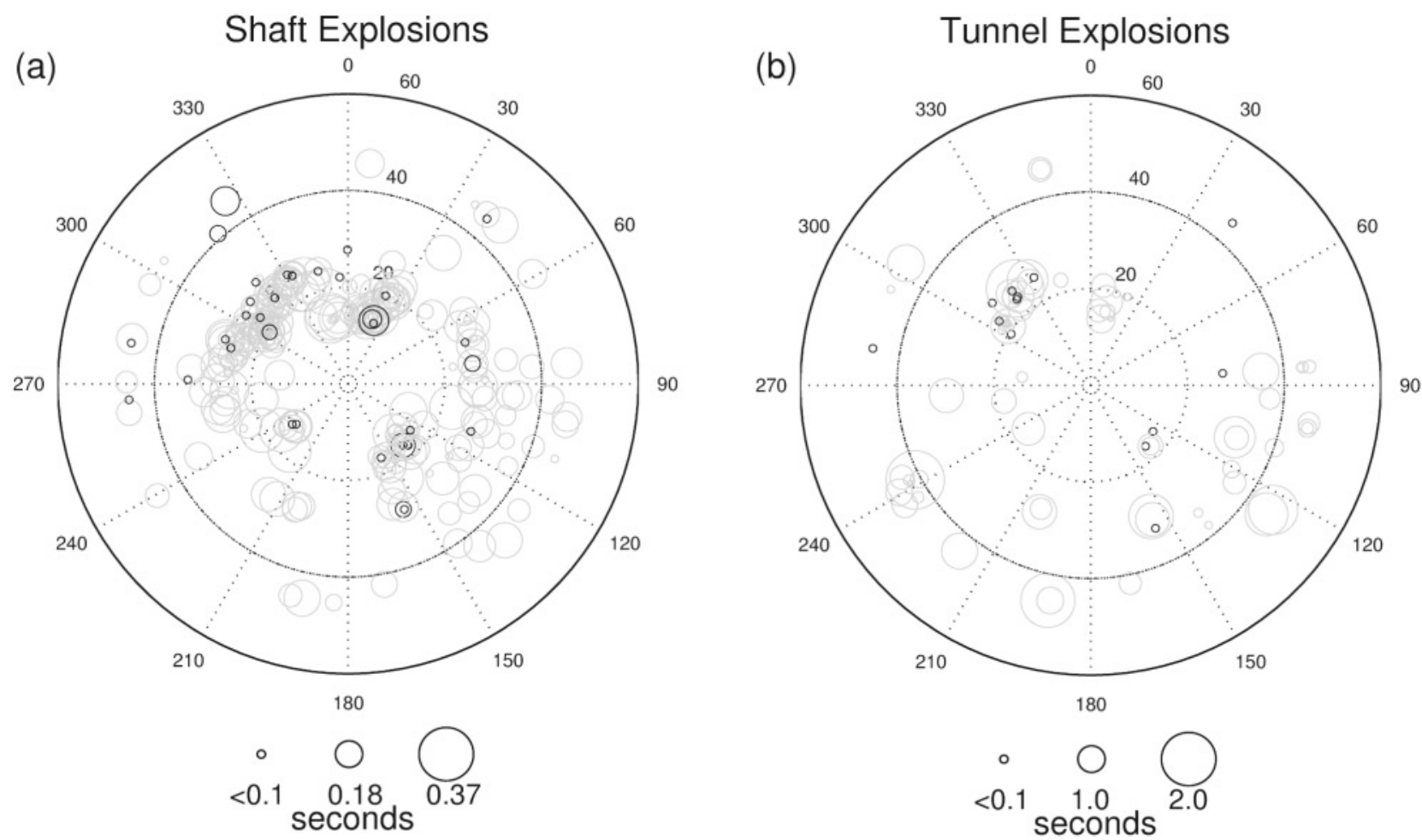

Figure 6. Polar plots (radius $=$ takeoff angles) of final rms differential-time residuals computed at each station for (a) shaft events and (b) tunnel events. Gray circles show phase-pick rms residuals, and black circles cross-correlation rms residuals. Solid dotted circle at $40^{\circ}$ indicates approximate area outside which the data are regional. Note the different scales for the two plots.

(T3), and $1502 \mathrm{~m}$ (T4). Figure $7 \mathrm{~b}$ indicates that the entrances are at the base of a northwest-trending, less than 2-km-wide ridge that reaches heights of more than $1800 \mathrm{~m}$.

All DD solutions (black dots) align along the ridge crest and locate within or close to the 1700 -m elevation contour. In contrast, the CMR locations for events 8412 and 8809 lie outside the 1700-m and 1600-m contours, respectively, approximately $2 \mathrm{~km}$ away from the tunnel entrances, with the ridge crest situated between the two. The DD error ellipses (black, Fig. 7b) of five events $(8305,8412,8809,9209$, and 9607) include the respective CMR location, with the excep- tion of one event (7610). The DD location for event 7610 is approximately $1.5 \mathrm{~km}$ southeast of the CMR location, close to tunnel entrances T3 and T4 (Fig. 7b). These entrances show eroded features on the IKONOS images (Fisk, 2002), indicating that they are more likely associated with older events, such as 7610 and 8412 . The fact that tunnel entrance T3 has the most eroded features (Fisk, 2002) suggests that event 7610 occurred in this tunnel, whereas event 8412 was conducted in tunnel T4, with less eroded features. This is supported by the observation that the northwest direction of tunnel entrance T4 leads directly to the DD location of event 

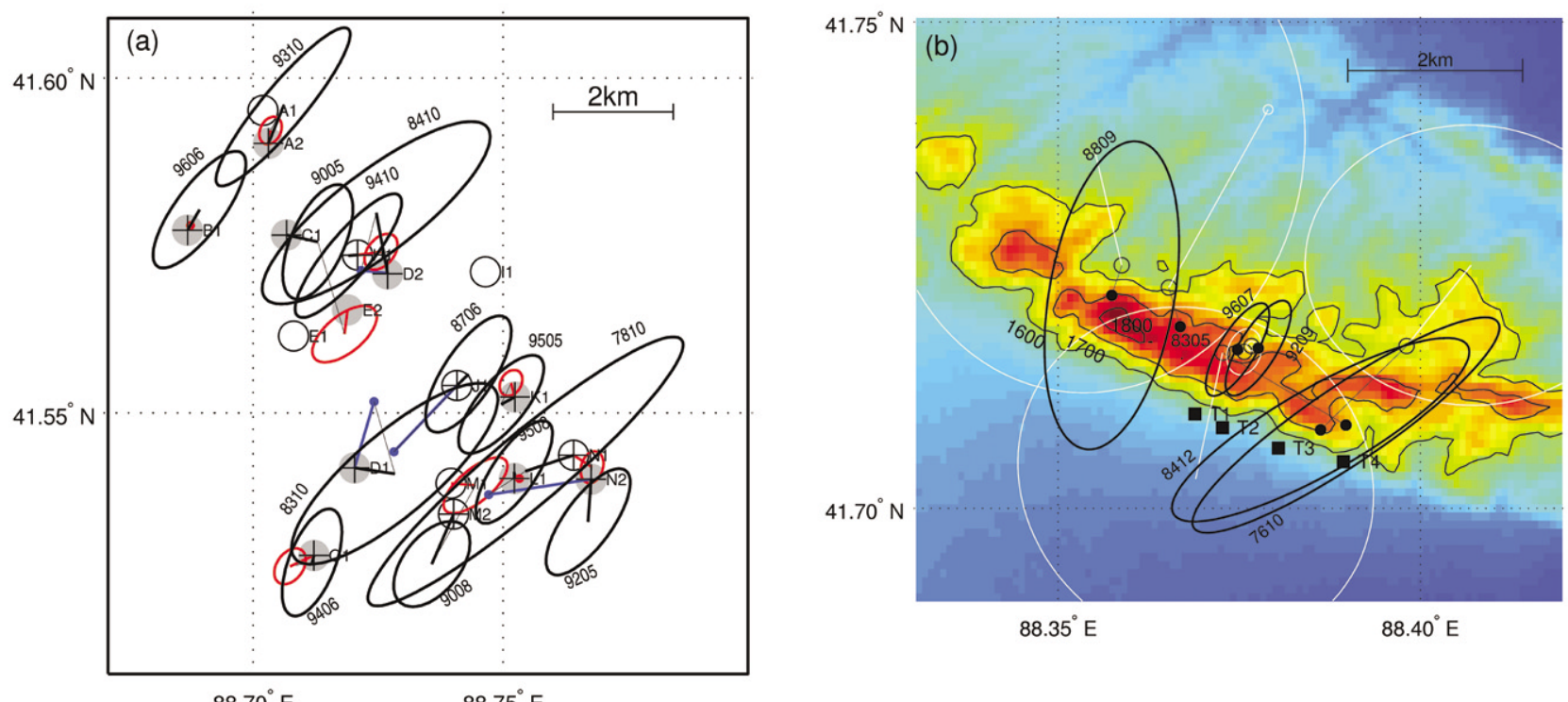

Figure 7. Comparison between previous results and results obtained in this study. (a) Solutions for shaft-explosion locations obtained in this study (black ellipses), from Fisk (2002) for events on or later than 1990 (red ellipses and dots), and from Bhattacharyya et al. (2002) for events prior to 1990 (blue dots). Black lines connecting DD locations and shafts represent shaft association made in this study, and red and blue lines those made by Bhattacharyya et al. (2002). Thin lines connect respective epicenters. The locations of shafts with clear (gray filled circles) and less clear (open circles) satellite features that support nuclear testing are indicated, with circle size proportional to their relative location uncertainty. Plus symbols $(+)$ mark shafts associated with nuclear-testing activity in this study. (b) Solutions for tunnel-explosion locations obtained in this study (black dots and ellipses) and from previous studies (white open circles and ellipses) (Gupta, 1995; Fisk, 2002; Bergman, as listed in Bhattacharyya et $a l ., 2002)$. Small open circles indicate the CMR locations. Black and white lines connect the DD locations and the locations from previous studies, respectively, to the corresponding CMR locations. Black squares indicate adit entrances from satellite imagery. Colors represent elevation, with the 1600-, 1700-, and 1800-m contour lines shown. DD ellipses are labeled by year and month of occurrence (see Table 3). For labels near shafts and adit entrances, see text.

8412 (see image T4, www.cmr.gov/rdss/resources/satimage/ LopNor/LopNorWest01/index.html). Tunnel entrances T1 and $\mathrm{T} 2$ show clear features on the satellite images, consistent with the nearby location of tests 9209 and 9607 (Fisk, 2002).

Although the original locations (white ellipses in Fig. 7b) used by Bhattacharyya et al. (2002) to adjust their preferred locations are consistent with the DD locations (except for event 8412), they show, for events prior to 1992, much larger error ellipses and locate outside the 1600-m contour. The relative locations of closely located events 9209 and 9607 match the ones of Fisk (2002) very well. (Note that the data used for these two events include the differential times used by Fisk, 2002.) Whereas Fisk (2002) chose event 9205 as a master event (with a fixed location) relative to which he located event 9607 , the DD approach allowed us to solve also for the location of all older neighboring events, relative to the two newer ones, through phase picks where waveforms were not available.

\section{Conclusions}

The DD shaft solutions indicate qualities at the GT1 level (ground truth known within $1 \mathrm{~km}$ ) for seven events, and GT2 (ground truth known within $2 \mathrm{~km}$ ) for the remaining six events (Table 3). These GT levels are obtained by adding the mislocation of the DD location from the assigned shaft and the absolute uncertainty of the shaft locations picked from satellite images $(\sim 500 \mathrm{~m})$. The $500-\mathrm{m}$ shaftlocation uncertainty is an upper bound and is likely to be smaller in particular for newer shafts with clearer features than older shafts that show erosion (Fisk, personal comm., 2004). It is quite possible, therefore, that the DD locations for events post-1990 are all of GT1 quality. GT levels for the tunnel events (Table 4) are generally higher than those for the shaft locations, mainly because no absolute reference frame is available. Based on the combination of the results from the DD analysis, the location of the adit entrances, and 
the high-resolution elevation data, we consider the tunnel events to be of GT2 quality. Event 8305, however, given its large error ellipse and thus its ability to move anywhere within the 1600-m contour, is of GT3 quality. Note that all our locations are consistent with previously published locations at their respective GT levels. This is also true for event 9005, to which both this study and the study of Fisk (2002) assign GT1; both solutions are separated by $1.5 \mathrm{~km}$.

The aim in this study was to resolve as well as possible the pattern of explosion locations by simultaneously relocating all events by using old and new data to estimate each event's location relative to all others. This study differs, therefore, from previous work on Lop Nor explosion locations in that a complete set of 19 locations is obtained, with relative locations between newer events to the accuracy of cross-correlation data derived from digital waveforms, and relative locations between older events to the accuracy of phase-pick data from regional and global bulletins. While the resulting pattern of DD locations is consistent with satellite imagery and elevation data, a few inconsistencies with previous results on shaft associations lead us to reassign shafts for four events. Our explosion-location estimates are at the GT2 level or better and are therefore suitable for calibration of stations of the International Monitoring System for effective monitoring of compliance with the Comprehensive Nuclear Test Ban Treaty. This study also demonstrates the performance of the double-difference approach, which so far has been applied to local seismic data, for relocating seismic events recorded at regional and teleseismic distances. Our location estimates for nuclear tests at Lop Nor may be further improved by adding additional waveform and/or phase-pick data, in particular for events that were recorded by only a few stations, such as the tunnel test of May 1983.

\section{Acknowledgments}

We thank Anyi Li for collecting some of the waveform data; Jian Zhang for translating Table 1; Bob Engdahl, Mark Fisk, and Eric Bergman for making their data available to us; and the ISC, the IRIS-DMC, and the CMR for their effort in archiving and providing seismic data. Mark Fisk and Eric Bergman are thanked for valuable comments on the manuscript. This study was supported by Contract DTRA 01-00-C-0031 of the Defense Threat Reduction Agency, with additional support for code development from National Science Foundation EAR-02-29832. This is Lamont-Doherty Earth Observatory Contribution Number 6650.

\section{References}

Bhattacharyya, J., B. Kohl, H. Israelsson, and B. Zuzolo (2002). Lop Nor underground nuclear explosions: summary of preferred locations and origin times, CMR Tech. Rept. CMR-02/01, Arlington, Virginia.

Douglas, A., P. Marshall, and K. Jones (1993). Body-wave magnitudes and locations of explosions at the Chinese test site, 1967-1989, AWE Rept. Number O 12/93, Atomic Weapons Establishment, Blacknest, Reading, U.K.

Engdahl, E. R., and E. Bergman (2001). Validation and generation of reference events by cluster analysis, in Proc. of 23rd Annu. DTRA/ NNSA Seism. Res. Rev., Jackson Hole, Wyoming, 1-5 October 2001.

Engdahl, E. R., R. van der Hilst, and R. Buland (1998). Global teleseismic earthquake relocation with improved travel times and procedure for depth determination, Bull. Seism. Soc. Am. 88, 722-743.

Fisk, M. D. (2002). Accurate locations of nuclear explosions at the Lop Nor test site using alignment of seismograms and IKONOS satellite imagery, Bull. Seism. Soc. Am. 92, 2911-2925.

Gupta, V. (1995). Locating nuclear explosions at the Chinese test site near Lop Nor, Sci. Global Security 5, 205-244.

Jordan, T. H., and K. A. Sverdrup (1981). Teleseismic location techniques and their application to earthquake clusters in the South-Central Pacific, Bull. Seism. Soc. Am. 71, 1105-1130.

Kennett, B. L. N., and E. R. Engdahl (1991). Travel times for global earthquake location and phase identification, Geophys. J. Int. 105, 429465 .

Ringdahl, F., P. D. Marshall, and R. W. Alewine (1992). Seismic yield determination of Soviet underground nuclear explosions at the Shagan River test site, Geophys. J. Int. 109, 65-77.

Schaff, D. P., G. H. R. Bokelmann, W. L. Ellsworth, E. Zanzerkia, F. Waldhauser, and G. C. Beroza (2004). Optimizing correlation techniques for improved earthquake location, Bull. Seism. Soc. Am. 94, $705-721$.

Waldhauser, F. (2001). HypoDD: a computer program to compute doubledifference hypocenter locations, U.S. Geol. Surv. Open-File Rep. 01113, Menlo Park, California.

Waldhauser, F., and W. L. Ellsworth (2000). A double-difference earthquake location algorithm: method and application to the northern Hayward fault, Bull. Seism. Soc. Am. 90, 1353-1368.

Yang, X., R. North, C. Romney, and P. G. Richards (2003). Worldwide Nuclear Explosions, Chap. 84 of International Handbook of Earthquake and Engineering Seismology, W. H. K. Lee, H. Kanamori, P. Jennings, and C. Kisslinger (Editors), Pt. B, Academic, New York, 1595-1599.

Lamont-Doherty Earth Observatory

Columbia University

P.O. Box 1000

Palisades, New York 10964

felixw@1deo.columbia.edu

Manuscript received 4 September 2003. 